well be renal in origin. These renal changes are brought about by the trueta shunt, initiated by uterine distention and mediated by the utero-renal reflex. The renal ischaemia causes both the hypertension and the biochemical changes found in toxaemia.

While forcibly distending the horn of a rabbit's uterus may provoke diversion of its renal flow it is not permissible to argue from this that twins, primigravidae, accidental haemorrhage or hydramnios can cause a similar disturbance. In actual' fact on this premise acute hydramnios should cause marked and inevitable toxaemia, but this is not so.

The evidence of the biochemist, deduced from renal function tests, is also not in favour of there being any diminution in cortical blood flow, but the author overrides this by stating 'the biochemist cannot in all seriousness claim that his methods are a meticulous index of renal physiological and pathological mechanisms.'

Eclampsia itself is not explained specifically in relation to the utero-renal reflex, but Macintosh's recent suggestion in relation to the abnormal electroencephalogram pattern found in these cases receives the author's support.

The chapter on anuria stands in marked contrast to the rest of the book. Here the trueta mechanism is critically studied both in relation to cortical necrosis and to tubular necrosis. The apparently contrary evidence of Bull and his workers concerning renal flow in anuria is discussed. The treatment advised is also sound, although critical analysis of O'Sullivan's and Spitzer's cases treated by paravertebral block reveal results not quite so satisfactory as the author suggests.

Most of the book is unfortunately written in a style which tends to be both ponderous and complex, although the author's insistence on the importance of the Oxford shunt in toxaemia emerges clearly enough. It must regretfully be doubted whether this book will live up to its publisher's claim to be 'the most important contribution yet made in the study of a difficult problem.'

D.W.S.G.

\section{CLINICAL CARDIOLOGY}

Edited by Franklin C. Massey, M.D. Pp. xiv + I, IOO, with 250 illustrations. London: Baillière, Tindall \& Cox. 1953. I02s. $6 \mathrm{~d}$.

This book comprises 28 chapters, the majority of which are written by different authors. The first roo pages or so are devoted to anatomy, physiology and the findings in the normal heart, followed by an unhelpful chapter on 'Cardiac Evaluation by Physical Diagnosis.' There is much that is redundant in this part of the book, though it contains a useful chapter on 'The Heart in Childhood.' The following section on roentgenology is good but is illustrated only by line drawings. Electrocardiography is dealt with fully, particularly in regard to theory and to myocardial infarction. It seems a pity, however, that in a modern textbook of cardiology all the chest leads illustrated should not $\frac{}{3}$ be $\mathrm{V}$ leads rather than $\mathrm{CR}$ and even CF.

Bailey, Glover and O'Neill contribute the chapter on surgery. Though this contains much of value and interest it is the longest in the book and is perhaps $\overrightarrow{\vec{F}}$ too long even in these days for a medical textbook ${ }^{-}$ The remaining clinical subjects are dealt with on anc aetiological basis; rheumatic, hypertensive, syphyl- $\frac{O}{\bar{c}}$. itic, coronary and pulmonary heart disease. Most $\frac{\widehat{\sigma}}{\widetilde{\sigma}}$ of these chapters might well have been condensed; $\stackrel{\mathbb{Q}}{\complement}$ there is repetition and sometimes contradiction, 'rheumatic pericarditis results in constrictive peri- $\rightarrow$ carditis '- rheumatic lesions never result in. chronic constrictive pericarditis.' The inclusion of $\overrightarrow{ }$ certain congenital heart lesions (Fallot's tetralogy and septal defects) in the section on pulmonaryo heart disease is, to say the least of it, somewhat unorthodox.

The most serious fault in this book is the difficulty or impossibility of obtaining adequate information $\omega$ on particular lesions. Thus on looking up mitral $\vec{N}$ stenosis in the index one is referred to five differentiv chapters, and at the end of a long search the in- $\vec{N}$ formation is far from complete. Nowhere is there응 a full account of the physical signs of this important disease.

It is difficult to say to whom this work would? appeal; for those who have already some special knowledge of cardiology there is much that is ro- $\overrightarrow{0}$ dundant, and for those who have not, there gis? insufficient sound clinical description and too mueho technical detail.

$$
\text { G.T.T. }
$$

\section{SURGERY OF REPAIR AS APPLIED TO HAND INJURIES}

By B. K. BaNK, M.S., F.R.C.S., F.R.A.C.S., and ${ }^{3}$ A. R. WAKEFIELD, M.S., F.R.C.S., F.R.A.C.S. Pp. xiv +256 , with 188 illustrations. Edinburgh: E. \& S. Livingstone, Ltd. 1953. 40s.음

Success in the management of hand injuries callsfor balanced judgment, technical precision and meticulous after care; attributes of experience which is often hard won and lengthy in acquisition. For, although there is an increasing growth of special centres for these cases, much of this important work has, of necessity, to be undertaken elsewhere. Bank and Wakefield, in writing on theo basis of their own vast experience, have produced an excellent book which should be of value to all re- $N$ sponsible for the care of the injured hand.

In disclaiming any pretence to an exhaustive $N$ treatise and by the avoidance of lengthy dissertationc on controversial issues, the authors are at once lucido and, above all, practical. This practical approacho is evident throughout the book from the instructive section on examination of the injured hand, a modeles of careful appraisal, to the details of after care and rehabilitation. The problem of choice of procedure

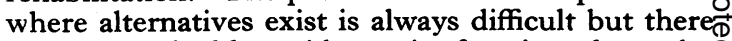
is much valuable guidance in forming these de- $\frac{\rho}{9}$ 